\title{
Study on Properties of Polytetrafluoroethylene Doped CoMoP Alloy Films Prepared by Plating Method
}

\author{
Kangchen Shao*, Hongyuan Shi \\ College of Aeronautical Materials Engineering, Xi'an Aeronautical Polytechnic Institute, Xi'an, Shanxi, \\ 710089, China \\ *E-mail: shaokangchennano@126.com
}

Received: 23 September 2021 / Accepted: 3 November 2021 / Published: 6 December 2021

\begin{abstract}
Polymer PTFE was added into the plating bath to prepare CoMoP/PTFE by plating method. Deposition rate, thickness, friction coefficient, magnetic performance and corrosion resistance of CoMoP/PTFE alloy film was investigated. PTFE is a kind of polymer materials with lower friction coefficient and higher impedance. The PTFE doped in the CoMoP/PTFE could greatly increase corrosion resistance and magnetic performance. The CoMoP/PTFE alloy film obtained from the bath with $15 \mathrm{~g} / \mathrm{L}$ PTFE has lower friction coefficient, optimal corrosion resistance and great magnetic performance. Surface morphology of the CoMoP/PTFE alloy film is a kind of typical nodular particles. PTFE is beneficial to reduce grain size of CoMoP/PTFE resulting in denser surface morphology. However, excessive PTFE in the plating bath tends to agglomerate resulting in the decrease of deposition rate and deterioration of film quality that contribute directly to the decrease of corrosion resistance and magnetic performance.
\end{abstract}

Keywords: Polymer PTFE; Plating method; CoMoP/PTFE alloy films; Corrosion resistance

\section{$\underline{\text { FULL TEXT }}$}

(C) 2022 The Authors. Published by ESG (www.electrochemsci.org). This article is an open access article distributed under the terms and conditions of the Creative Commons Attribution license (http://creativecommons.org/licenses/by/4.0/). 